See Article page 1484.

\section{Commentary: Wedge resection for limited-stage small cell lung cancer: Not an acceptable modality for curative intent}

Michael Lanuti, MD

In the absence of more contemporary randomized trials, pulmonary resection for limited-stage small cell lung cancer (SCLCL) has become more widely accepted in thoracic oncology by virtue of published retrospective series that demonstrate long-term overall survival of $\sim 50 \%$ at 5 years. $^{1,2}$ These are often highly selected patients in the absence of N2 disease in whom superior outcomes were observed primarily with lobectomy. In this edition of the Journal, Raman and colleagues ${ }^{3}$ query the National Cancer Database (NCDB) for surgically resected T1-2N0M0 SCLC from 2004 to 2015. The low number of patients meeting inclusion criteria $(\mathrm{n}=1948)$ in this analysis that spans 15 years highlights how infrequent surgery is used. Patients were stratified by wedge, segment, or lobectomy. The primary outcome was overall survival and secondary outcomes included positive margins (absence of R0 resection) or pathologic nodal upstaging. The groups consisted of $619(32 \%)$ who underwent wedge resection, 96 (5\%) segmentectomy, and $1233(63 \%)$ lobectomy. For a study that sought to dissect the impact of wedge resection versus segmentectomy for the sublobar resection group, the number of segmentectomies was small, which potentially weakens the internal validity of the study. Nonetheless, as expected, median overall survival improved from wedge to segment to lobectomy (49 months, 5-year overall survival $45 \%$ ), and wedge resections were associated with more positive margins. Of note, segmentectomy experienced similar survival to lobectomy and margin status was also similar. The authors were not able to stratify outcomes by tumor size and type of resection.

\footnotetext{
From the Division of Thoracic Surgery, Massachusetts General Hospital, Boston, Mass.

Disclosures: Author has nothing to disclose with regard to commercial support. Received for publication March 15, 2020; revisions received March 15, 2020; accepted for publication March 16, 2020; available ahead of print April 5, 2020. Address for reprints: Michael Lanuti, MD, 55 Fruit St, Founders 7, Boston, MA 02114 (E-mail: mlanuti@mgh.harvard.edu).

J Thorac Cardiovasc Surg 2021;161:1493-4 $0022-5223 / \$ 36.00$

Copyright (C) 2020 by The American Association for Thoracic Surgery https://doi.org/10.1016/j.jtcvs.2020.03.112
}

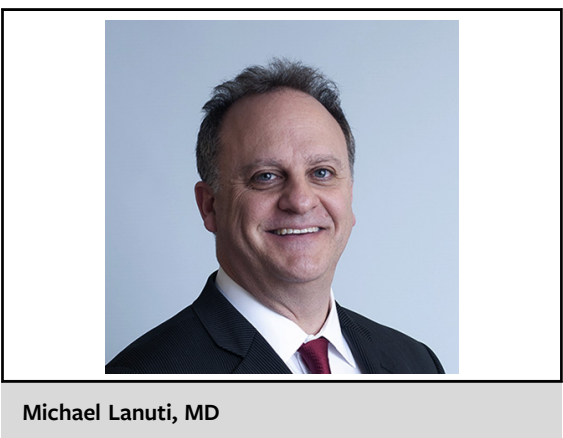

CENTRAL MESSAGE

Anatomic resection is associated with superior outcomes in the multimodality treatment of limited-stage small cell lung cancer in the absence of pathologic intrathoracic nodal disease.

This study largely confirms what is understood for non-small cell lung cancer regarding type of resection and overall survival. Disease-free survival was not available in this analysis and can be construed as a weakness. Patients undergoing wedge resection experienced worse outcomes, but it is not clear whether this observation is attributable to more comorbid disease or cancer death (hence the need for disease-free survival). The lack of invasive staging criteria or even the use of positron emission tomography for staging severely limits this analysis. Of interest, the NCDB does not provide granularity to understand the contribution of prophylactic cranial irradiation to survival in patients undergoing curative surgery. As the authors acknowledge, selection bias is unavoidable in the NCDB and remains a real challenge when comparing a wedge cohort (which is clearly a compromise in a patient being surgically treated for small cell lung cancer) with anatomic resection. Most would agree that wedge resection would not be acceptable for SCLC (except for diagnostic purposes only), and the data in this analysis corroborate the notion that this operation is no better than definitive chemo/radiotherapy. If anything, this is an observation that is clearly worth reporting.

\section{References}

1. Combs SE, Hancock JG, Boffa DJ, Decker RH, Detterbeck FC, Kim AW Bolstering the case for lobectomy in stages I, II, and IIIA small-cell lung cancer using the National Cancer Data Base. J Thorac Oncol. 2015;10:316-23. 
2. Yang CJ, Chan DY, Shah SA, Yerokun BA, Wang XF, D'Amico TA, et al. Long-term survival after surgery compared with concurrent chemoradiation for node-negative small cell lung cancer. Ann Surg. 2018;268:1105-12.
3. Raman V, Jawitz OK, Yang CFJ, Voigt SL, D'Amico TA, Harpole DH, et al. The effect of extent of resection on outcomes in patients with limited stage small cell lung cancer. J Thorac Cardiovasc Surg. 2021;161:1483-92.e5.
See Article page 1484 .

\section{Commentary: How much is enough? The extent of resection in small cell lung cancer}

\author{
James J. Choi, MD, MPH, and James Huang, MD
}

Small cell lung cancer (SCLC) is generally seen as a nonsurgical disease, and the mainstay of treatment for limited-stage disease is definitive concurrent chemoradiation. ${ }^{1,2}$ However, there exists a subgroup of patients with limited-stage disease for whom surgery may be an option. The National Comprehensive Cancer Network guidelines suggest that patients with T1-2N0 stage I disease can be considered for lobectomy and mediastinal lymph node dissection, followed by adjuvant chemotherapy in all patients, with mediastinal radiotherapy for those with nodepositive disease. $^{3}$

Raman and colleagues ${ }^{4}$ performed a retrospective analysis of the National Cancer Database (NCDB), investigating survival outcomes on the basis of extent of surgical resection in patients with SCLC. They found poorer survival among patients who underwent wedge resection, compared with lobectomy, and that survival was similar between lobectomy and segmentectomy. Along with a study by Liu and colleagues, ${ }^{5}$ this is one of the first studies to provide more granularity with regard to different sublobar resections for SCLC. Although the sample size was small, with only $5 \%$ of patients undergoing segmentectomy, a propensity score-matched analysis suggested similar survival to lobectomy. In addition, the authors demonstrated that survival with wedge resection alone was no better than

From Thoracic Service, Department of Surgery, Memorial Sloan Kettering Cancer Center, New York, NY.

Disclosures: Authors have nothing to disclose with regard to commercial support.

Received for publication March 4, 2020; accepted for publication March 4, 2020; available ahead of print March 19, 2020.

Address for reprints: James Huang, MD, Thoracic Service, Department of Surgery, Memorial Sloan Kettering Cancer Center, 1275 York Ave, New York, NY 10065 (E-mail: huangj@mskcc.org).

J Thorac Cardiovasc Surg 2021;161:1494-5 0022-5223/ $\$ 36.00$

Copyright $₫ 2020$ Published by Elsevier Inc. on behalf of The American Association for Thoracic Surgery

https://doi.org/10.1016/j.jtcvs.2020.03.010

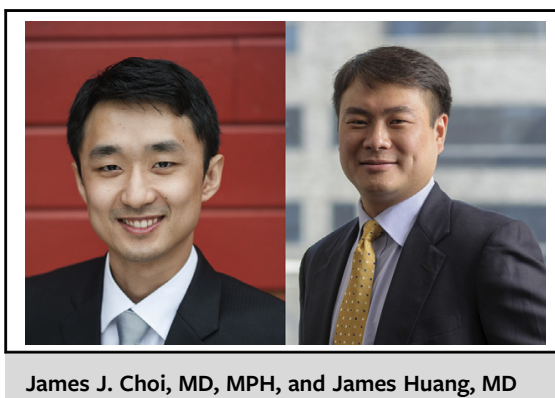

CENTRAL MESSAGE

Segmental and lobar resection are associated with similar survival in patients with resectable CT1-2No stage I SCLC.

when concurrent chemoradiation was given, and they suggest that wedge resection alone is not an acceptable treatment strategy. Interestingly, adjuvant therapy was underused in the wedge resection group, with only $35 \%$ of patients receiving adjuvant chemotherapy and $29 \%$ of patients receiving thoracic radiation. Adjuvant therapy use was surprisingly no better in the segmentectomy and lobectomy groups.

Despite these important findings, the elephant in the room remains selection bias. The authors do acknowledge this directly, but the information necessary for the surgeon to decide on extent of resection is simply not available through the NCDB. Data on tumor factors, such as tissue diagnosis, location in the lobe, and clinical staging, were unavailable. Patient factors were also missing, including pulmonary function and measures of frailty. It seems unlikely that all patients who underwent wedge resection could have also undergone lobectomy, and vice versa.

The authors attempted to account for node status by performing a subgroup analysis including patients with only pathologic node-negative disease, with no significant changes in the conclusion regarding survival outcomes. In 